\title{
The role of histone deacetylase inhibitors in regulation of Akt/GSK-3 $\beta$ signaling pathway in mice following transient focal cerebral ischemia ${ }^{1}$
}

\author{
Bo Zhao', Lian Liu", Yan Leng'"', Quan Yuan'v, Jiabao Hou'v, Yang Wu'", Wenwei Gaov
}

'Doctor of Medicine, Department of Anesthesiology, Renmin Hospital, Wuhan University, China. Acquisition and interpretation of data, manuscript writing.

"Master of Medicine, Department of Anesthesiology, Renmin Hospital, Wuhan University, China. Acquisition and interpretation of data, critical revision.

I'Doctor of Medicine, Department of Anesthesiology, Renmin Hospital, Wuhan University, China. Acquisition and interpretation of data.

IV Master of Medicine, Department of Anesthesiology, Renmin Hospital, Wuhan University, China. Acquisition and interpretation of data.

${ }^{\vee}$ Doctor of Medicine, Department of Critical Care Medicine, Renmin Hospital, Wuhan University, China. Design and supervised all phases of the study.

\section{Abstract}

Purpose: To investigate whether the neuroprotective effect of TSA on cerebral ischemia reperfusion injury is mediated by the activation of Akt/GSK-3 $\beta$ signaling pathway.

Methods: Mice were randomly divided into four groups $(n=15)$ : sham group (S); ischemia reperfusion group (IR); ischemia reperfusion and pretreated with TSA group (IR+T); ischemia reperfusion and pretreated with TSA and LY294002 group (IR+T+L). The model of cerebral ischemia reperfusion was established by $1 \mathrm{~h}$ of MCAO following 24h of reperfusion. TSA (5mg/ $\mathrm{kg}$ ) was intraperitoneally given for 3 days before MCAO, Akt inhibitor, LY294002 (15 nmol/kg) was injected by tail vein 30 min before the MCAO.

Results: TSA significantly increased the expression of p-Akt, p-GSK-3 $\beta$ proteins and the levels of SOD, Bcl-2, reduced the infarct volume and the levels of MDA, ROS, TNF- $\alpha, I L-1 \beta, B a x$, Caspase-3, TUNEL and attenuated neurological deficit in mice with transient MCAO, LY294002 weakened such effect of TSA dramatically.

Conclusions: TSA could significantly decrease the neurological deficit and reduce the cerebral infarct volume, oxidative stress, inflammation, as well as apoptosis during cerebral ischemia reperfusion injury, which was achieved by activation of the Akt/GSK-3 $\beta$ signaling pathway.

Key words: Histone Deacetylases. Glycogen Synthase Kinase 3 beta. Brain Ischemia. Reperfusion Injury. Mice. 


\section{Introduction}

Stroke, one of the serious diseases that threaten human health, is a pathological condition due to the occlusion of blood vessels which providing oxygen and essential nutrients to the brain, and it is characterized with high incidence, high morbidity and high mortality ${ }^{1}$. In all cases, stroke eventually leads to nerve cells dysfunction or death. The severity of brain damage is closely related with the length of ischemic time and the degree of ischemia ${ }^{2}$. Current clinical treatment for ischemic stroke is regaining blood supplies to the ischemic brain tissue, but more and more clinical cases show that this treatment may alleviate the situation of cerebral ischemia in a short time, but it is very limit for improvement of neurological function, and even aggravate the injury, this phenomenon is called cerebral ischemia reperfusion injury (CIRI) ${ }^{3}$.

Recent studies have shown that the gene expression in ischemic stroke is abnormal, and acetylation is one of important mechanisms for gene transcription, regulation and expression, which mainly consists of histone acetylase (HAT) and histone deacetylase (HDAC) ${ }^{4,5}$. HDAC plays a significant part in epigenetic related signaling pathways which can participate in various life activities by regulating the balance of acetylation and deacetylation by histone and non-histones, including cell growth, differentiation, death, as well as the interactions and inflammations between cells and interstitial ${ }^{6}$.

Akt/GSK-3ß pathway is an important signaling pathway in reperfusion injury salvage kinase (RISK). This pathway is considered to be a key to regulating cell survival, proliferation and growth ${ }^{7}$. Akt/GSK-3 $\beta$ pathway is also plays an important role in many diseases processes ${ }^{8}$. Studies have shown Akt/GSK-3 $\beta$ pathway is involved in oxidative stress, apoptosis and inflammatory reactions, and it is also closely related with ischemia reperfusion injury ${ }^{9,10}$.

Studies have shown that the HDAC inhibits transcription by making it difficult for gene promoters to get close to the transcriptional regulatory component, which leads to brain damage. Histone deacetylase inhibitors (HDACl) can inhibit HDAC activity and produce brain protection ${ }^{11,12}$. However, it is unclear whether HDACl has a protective effect on the Akt/GSK-3 $\beta$ signaling pathway. This study was designed to investigate the role of $\mathrm{HDACl}$ in the regulation of Akt/GSK-3 $\beta$ pathway in the cerebral ischemia reperfusion injury.

\section{- Methods}

This study was approved by the ethics committee of the Renmin Hospital, Wuhan University, China. All animal procedures received the approval of the Wuhan University Animal Care and Use Committee and followed the Principles of Laboratory Animal Care and are in accordance with the Guide for the Care and Use of Laboratory Animals by the National Institutes of Health.

Male Balb/c mice (10-12 weeks old) were maintained on sterile, standard laboratory chow and water ad libitum in individual ventilated cages under specific pathogenfree (SPF) conditions, with a maintained temperature of $22^{\circ} \mathrm{C}$, relative humidity of $50 \pm 15 \%$, and a 12 -hour light/12-hour dark cycle, in the animal facility of the Experimental Research Centre of Wuhan University.

\section{Experimental protocols}

Sixty mice were randomly divided into four groups: (1) sham operated mice (S); (2) mice subjected to MCAO (IR); (3) mice subjected to MCAO, pretreated with TSA (IR+T); (4) mice subjected to MCAO, pretreated with TSA and LY294002 (IR+T+L). Mice in each group except 
that in the sham group underwent $1 \mathrm{~h}$ of MCAO following $24 \mathrm{~h}$ of reperfusion. TSA $(5 \mathrm{mg} / \mathrm{kg})$ was intraperitoneally given for 3 days before MCAO, Akt inhibitor, LY294002 (15 nmol/kg) was injected by tail vein $30 \mathrm{~min}$ before the MCAO.

\section{Model of focal cerebral ischemia}

Mice were anesthetized with $2 \%$ isoflurane in $70 \% \mathrm{~N}_{2} \mathrm{O}$ and balance $\mathrm{O}_{2}$ by facemask. Cerebral ischemia was induced by $1 \mathrm{~h}$ of MCAO with a silicone- coated 6-0 monofilament followed by $24 \mathrm{~h}$ of reperfusion. Sham-operated mice underwent an identical procedure, without inserting sutures. Rectal temperature was maintained at $37 \pm 0.5^{\circ} \mathrm{C}$ with a heating pad. Heart rate, oxygen saturation, and respiratory rate were monitored continuously. Animals with no observable deficits immediately after ischemia, those that died before $24 \mathrm{~h}$ were excluded from analysis.

The histopathology of brain tissue

After $24 \mathrm{~h}$ of reperfusion, mice were anesthetized with isoflurane and executed, and their brains were fixed with $4 \%$ formaldehyde solution for $24 \mathrm{~h}$, embedded in paraffin and cut into $4 \mu \mathrm{m}$ pieces by microtome, and stained with haematoxylin and eosin stain (H\&E). The HE staining was quantified under a BX51 microscope ( $\times 400$, Olympus Inc, Japan).

\section{TTC staining}

After $24 \mathrm{~h}$ of reperfusion, mice were killed on ice and their brains were removed and frozen at $-20^{\circ} \mathrm{C}$ for $10 \mathrm{~min}$, then sectioned coronally with a rodent brain slicer matrix (Zivic Instruments, Pittsburgh, PA). Sections were incubated in 2\% 2,3,5-triphenyletrazolium chloride(TTC) (Sigma Inc, USA). After the staining, the infarct tissue was white and the normal tissue was red.

\section{Determination of oxidative stress}

MDA level and SOD activity were detected using commercial kits (Jiancheng Bioengineering, China). Tissue homogenate was prepared according to the user manual. Briefly, brain tissuewas homogenized in 10vol $(\mathrm{w} / \mathrm{v})$ ice-cold 0.1MPBS. Then the homogenate was centrifuged at $4000 \times \mathrm{g}$ for $10 \mathrm{~min}$ and the supernatant was used for MDA level and SOD activity .

Mitochondria-generated ROS (Jiancheng Bioengineering, China): protein were incubated in reaction buffer, Malate and glutamate were added as substrates. After $40 \mathrm{~min}$ incubation at $37^{\circ} \mathrm{C}$, the formation of the oxidized fluorescent product dichloro-fluorescein was monitored with excitation at $488 \mathrm{~nm}$ and emission at $525 \mathrm{~nm}$. The results were expressed as arbitrary fluorescence units per $\mathrm{mg}$ protein $(\mathrm{U} / \mathrm{mg})$.

\section{ELISA to detect TNF- $\alpha, I L-16$}

Brain samples were pulverized using a porcelain mortar and pestle under liquid nitrogen. Then the tissues were incubated in a lysis buffer for $1 \mathrm{~h}$ at $4^{\circ} \mathrm{C}$. After $10 \mathrm{~min}$ centrifugation at $10000 \mathrm{~g}$, the supernatant was collected for ELISA. The levels of TNF- $\alpha$ and IL$1 \beta$ were measured using an ELISA kit following the manufacturer's specification (Boster Biotech Inc. China). Each tested sample was normalized by its protein concentration in $\mathrm{mg}$ level.

Immunohistochemical staining of $\mathrm{Bax}, \mathrm{BCl}-2$ and Caspase-3

Sections were dewaxed, rehydrated and then incubated in PBS for 10min to block endogenous peroxidase activity. Sections were subjected to antigen retrieval by boiling sections in $10 \mathrm{mM}$ sodium citrate buffer in a microwave for $20 \mathrm{~min}$. After cooling, sections 
were blocked in normal goat serum (1:10, ZSGB Biotech Inc. China) for $10 \mathrm{~min}$, then incubated overnight at $4^{\circ} \mathrm{C}$ with rabbit anti- Bax, Bcl-2, Caspase-3 polyclonal antibodies(1:100, ZSGB Biotech Inc. China). After being washed with PBS, sections were incubated for $10 \mathrm{~min}$ with biotinylated goat anti-rabbit IgG (1:10, ZSGB Biotech Inc China). Staining was visualized using diaminobenzidine as a substrate. The number of positive cells was quantified under a BX51 microscope ( $\times 400$, Olympus Inc, Japan).

\section{TUNEL staining for cell apoptosis}

Paraffin embedded sections were dewaxed and rehydrated, then incubated in $20 \mu \mathrm{L} / \mathrm{mL}$ proteinase $\mathrm{K}$ for $15 \mathrm{~min}$. TUNEL was accomplished using an in situ cell death detection kit (Roche Inc, USA). After immersion in equilibration buffer for $10 \mathrm{~min}$, sections were incubated with TdT and dUTP-digoxigenin, then washed before incubation in antidigoxigenin-peroxidase solution, and colored with diaminobenzidine- $\mathrm{H}_{2} \mathrm{O}_{2}$ solution. The number of TUNEL-positive cells was quantified under the BX51 microscope $(\times 400$, Olympus Inc, Japan).

\section{Western blot analysis}

Brain tissue was sampled and homogenized with $1000 \mu$ l lysis buffer. The homogenates was centrifuged at $12000 \mathrm{~g}$ at $4{ }^{\circ} \mathrm{C}$ for $15 \mathrm{~min}$; equivalent amountsof total protein extracts were loaded into each lane and separated by $10 \%$ SDS gels, then transferred onto PVDF membrane. The membrane was blocked with $5 \%$ BSA for $1 \mathrm{~h}$ and incubated with the following primary rabbit monoclonal antibodies: Akt, p-Akt, GSK-3 $\beta$ and p-GSK$3 \beta$ (1:1000, Cell Signaling Technology, USA) diluted in $5 \% \mathrm{w} / \mathrm{v} \mathrm{BSA}$, and overnight at $4{ }^{\circ} \mathrm{C}$. The membrane was incubated with fluorescent tags Goat anti-Rabbit polyclonal IgG (1:10000, LI-COR Inc, USA) for $1 \mathrm{~h}$ followed by additional washing. GADPH was chosen as a loading control to further assure the same volume for all the samples.

\section{Statistical analysis}

Data was presented as mean $\pm S D$ and analyzed using SPSS17.0 software. The differences associated with main sources of variation were tested using one-way analysis of variance (ANOVA). When the $F$ statistic was significant for ANOVA comparisons, the differences between individual means were tested for significance using Bonferroni tests. $P<0.05$ was considered statistically significant.

\section{Results}

\section{The histopathology of brain tissue}

Microscopically, we found that when compared with $S$ group, the neurons in IR group were irregular, with uneven distribution of cytoplasm and vacuolization, and the nucleation was dissolved or disappeared. In $\mathrm{IR}+\mathrm{T}$ group, the neurons were relatively orderly, with complete cytoplasm, abundant cytoplasm, and a relatively clear structure. But in $I R+T+L$ group, the protective role of TSA to maintain the normal morphological characteristics was weakened (Figure 1). 


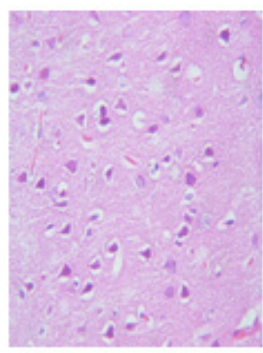

$\mathrm{S}$ group

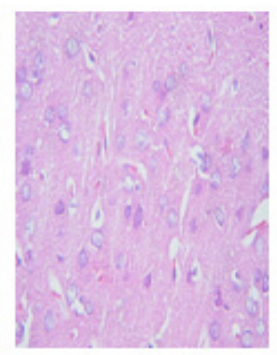

IR group

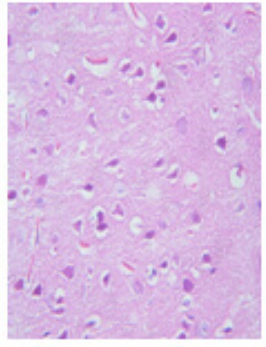

IR+T group

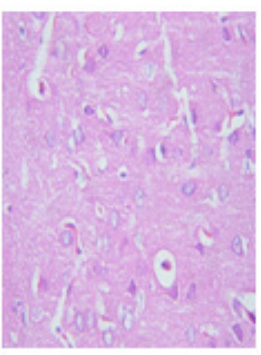

$\mathrm{IR}+\mathrm{T}+\mathrm{L}$ group

Figure 1 - The cerebral histopathology haematoxylin and eosin staining. Microscopic observation showed that the cortical neurons were arranged in neat rows with abundant cytoplasm, and the nuclei were round and basophilic in S group. The structures of the cortical neurons were damaged, the cytoplasm was light red with uneven distribution and vacuoles, nuclei were condensed in IR group. In IR+T group, however, the cell structure was normal. Most of the neurons had complete membrane integrity and the nuclei were clear. In $\mathrm{IR}+\mathrm{T}+\mathrm{L}$ group, it seems almost like IR group.

$S$ group=sham group, IR group=cerebral ischemia reperfusion group, IR+T group= cerebral ischemia reperfusion+TSA (HDAC inhibtor) group, $I R+T+L$ group= cerebral ischemia reperfusion group $+T S A+L Y 294002$ (Akt inhibitor) group.

\section{TTC staining}

Mice in the sham group had little infarction as expected, while other groups had different extent of cerebral infarction. TSA in IR+T group significantly decreased the infarction volume when compared with IR group $(P<0.05)$. But in the $I R+T+L$ group by joint application of TSA and LY294002, could attenuated such neuroprotective effects of TSA significantly when compared with $\mathrm{IR}+\mathrm{T}$ group $(P<0.05)$ (Figure 2).

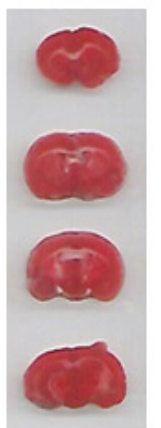

S group

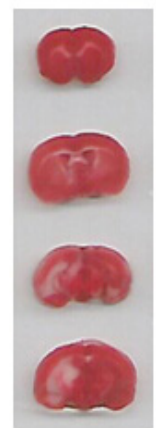

IR group

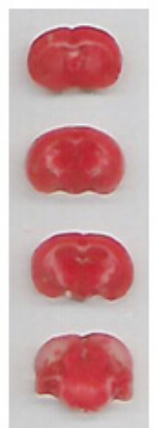

$\mathrm{IR}+\mathrm{T}$ group $\mathrm{IR}+\mathrm{T}+\mathrm{L}$ group

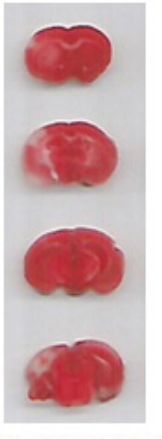

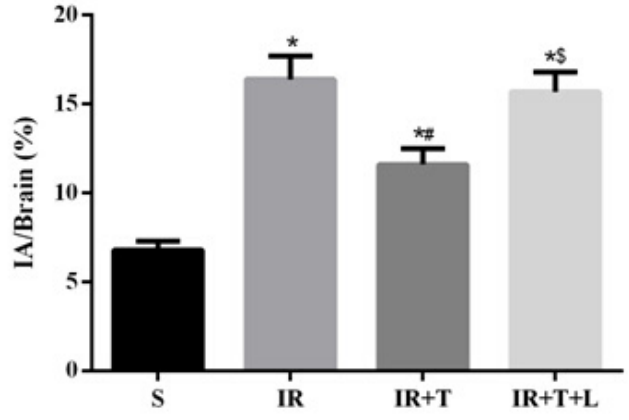

Figure 2 - The cerebral TTC staining. Mice in the sham group had little infarction as expected, while other groups had different extent of cerebral infarction. TSA in IR+T group significantly decreased the infarction volume when compared with IR group $(P<0.05)$. But in IR+T+L group by joint application of TSA and LY294002, could attenuated such neuroprotective effects of TSA significantly when compared with IR+T group $(P<0.05)$. ${ }^{*} P<0.05$, vs. S group; ${ }^{P} P<0.05$, vs. IR group; ${ }^{\$} P<0.05$, vs. IR+T group.

\section{Determination of oxidative stress}

Compared with $S$ group, MDA and ROS increased, while SOD decreased in IR group $(P<0.05)$. TSA in IR+T group significantly decreased the expression of MDA and ROS, and increased SOD expression as compared with IR group $(P<0.05)$. However, in $I R+T+L$ group using TSA and LY294002 together, could decrease such antioxidant stress effects of TSA to a certain degree when compared with IR+T group $(P<0.05)$ (Figure 3 ). 

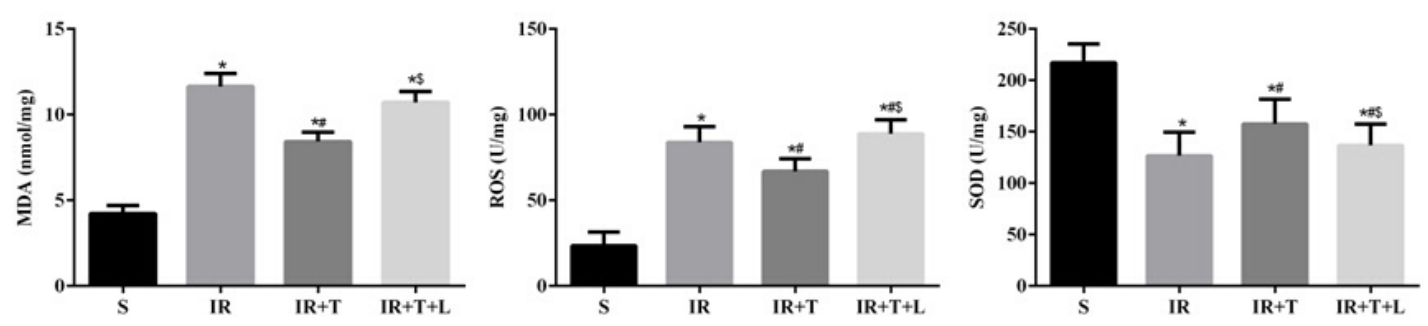

Figure 3 - Expression of oxidative stress in the brains (MDA, ROS, SOD). MDA, ROS, SOD are the important indicators of oxidative stress. In the research, it found that MDA and ROS expressions were significantly increased while the expressions of SOD were significantly decreased in IR group $(P<0.05)$. TSA in IR+T group significantly decreased the expression of MDA and ROS and increased SOD expression when compared with IR group $(P<0.05)$. However, in IR+T+L group, using TSA and LY294002 together, could decrease such antioxidant stress effects of TSA to a certain degree when compared with IR+T group $(P<0.05)$.

${ }^{*} P<0.05$, vs. S group; ${ }^{\sharp} P<0.05$, vs. IR group; ${ }^{\$} P<0.05$, vs. IR+T group.

Expression of $T N F-\alpha, I L-16$ in the brains

When compared with $S$ group, the levels of TNF- $\alpha, \mathrm{IL}-1 \beta$ in the brain tissue were increased in IR group $(P<0.05)$. Compared with IR group, the levels of TNF- $\alpha, I L-1 \beta$ in IR+T group were significantly lower when TSA was used $(P<0.05)$. While when TSA and LY294002 were jointed, the anti-inflammatory effect of TSA were abolished in $\mathrm{IR}+\mathrm{T}+\mathrm{L}$ group $(P<0.05)$ (Figure 4).
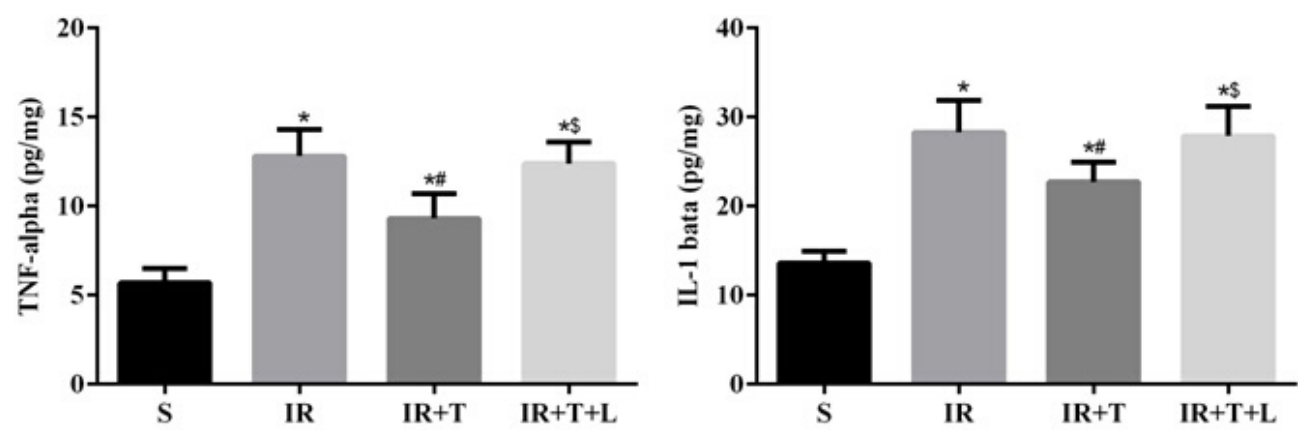

Figure 4 - Expression of inflammatory cytokines in the brains (TNF- $\alpha$, IL-1 $\beta$ ). TNF- $\alpha$, IL-1 $\beta$ are the important indicators of inflammatory cytokines. In the research, it found that TNF- $\alpha$, IL-1 $\beta$ expressions were significantly increased in IR group $(P<0.05)$. In contrast, TSA reversed these changes in IR+T group $(P<0.05)$. In IR+T+L group, the anti-inflammatory effect of TSA were abolished $(P<0.05)$.

${ }^{*} P<0.05$, vs. S group; ${ }^{\sharp} P<0.05$, vs. IR group; ${ }^{\$} P<0.05$, vs. IR+T group.

Expression of immunohistochemical in the brains (Bax, Bcl-2, Caspase-3)

In this research, we found that Bax and Casepase- 3 expressions were significantly increased while the expression of $\mathrm{Bcl}-2$ was significantly decreased in IR group $(P<0.05)$.
TSA in IR+T group significantly decreased Bax and Casepase-3 expressions and increased the expression of $\mathrm{Bcl}-2$ as compared with IR group $(P<0.05)$. But in $I R+T+L$ group, the antiapoptotic effects of TSA was decreased when compared with IR+T group $(P<0.05)$ (Figure 5$)$. 


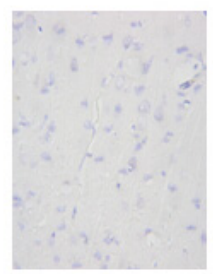

S group

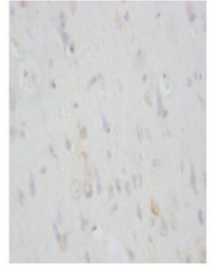

S group

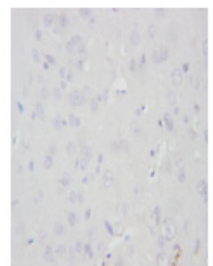

$\mathrm{S}$ group

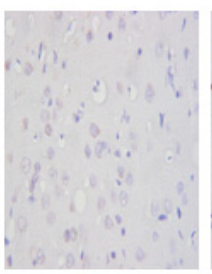

IR group

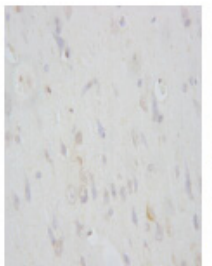

IR group

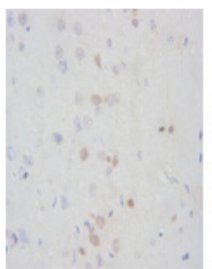

IR group

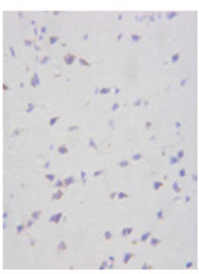

$\mathrm{IR}+\mathrm{T}$ group

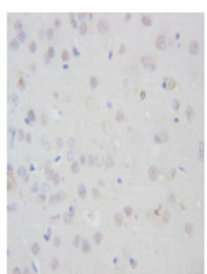

$\mathrm{IR}+\mathrm{T}$ group

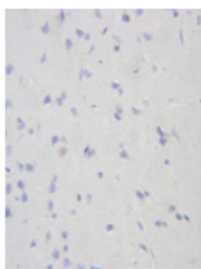

$\mathrm{IR}+\mathrm{T}$ group

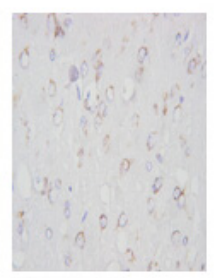

$\mathrm{IR}+\mathrm{T}+\mathrm{L}$ group

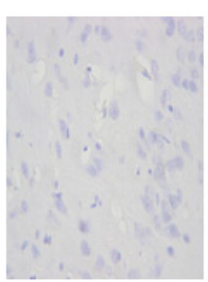

$\mathrm{IR}+\mathrm{T}+\mathrm{L}$ group

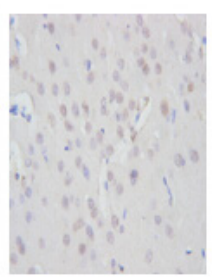

$\mathrm{IR}+\mathrm{T}+\mathrm{L}$ group
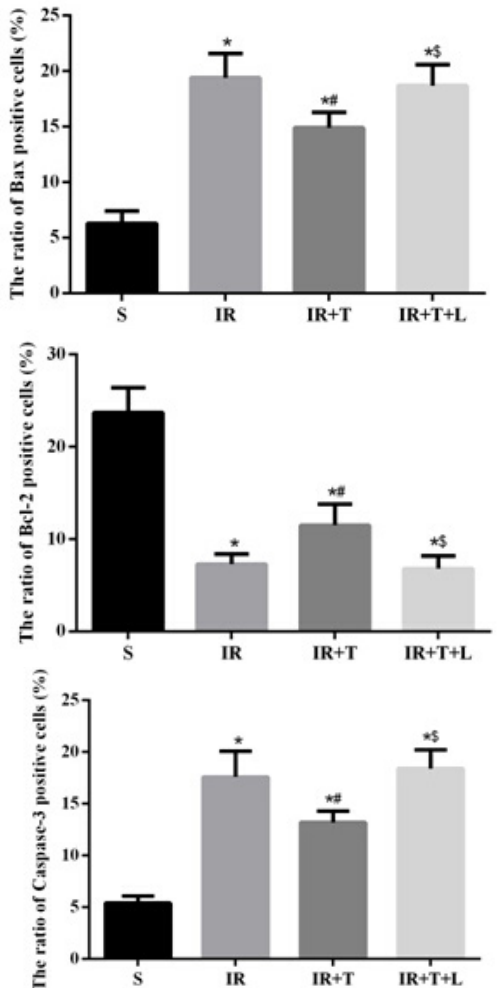

Figure 5 - Expression of immunohistochemical in the brains ( $\mathrm{Bax}, \mathrm{Bcl}-2, \mathrm{Caspase}-3$ ). $\mathrm{Bax}, \mathrm{Bcl}-2$ are belong to $\mathrm{Bcl}-2$ gene family, which is an essential factors for cell death, caspase- 3 is the important indicators of apoptosis response. In the research, it found that the expression of Bax, Caspase-3 were significantly increased while the expression of $\mathrm{BCl}-2$ was significantly decreased in IR group $(P<0.05)$. In contrast, TSA reversed these changes in protein expression in IR+T group $(P<0.05)$. In IR+T+L group, the consequence was no better than IR group $(P<0.05)$.

${ }^{*} P<0.05$, vs. S group; ${ }^{\sharp} P<0.05$, vs. IR group; ${ }^{\$} P<0.05$, vs. IR+T group.

\section{Expression of apoptosis in the brains (TUNEL)}

Compared with $\mathrm{S}$ group, the number of TUNEL positive cells in the brain tissue were increased in IR group $(P<0.05)$. Compared with
IR group, TUNEL in IR+T group were significantly lower $(P<0.05)$. While when LY294002 was used, the anti-apoptotic effect of TSA were abolished in $\mathrm{IR}+\mathrm{T}+\mathrm{L}$ group $(P<0.05)$ (Figure 6$)$.

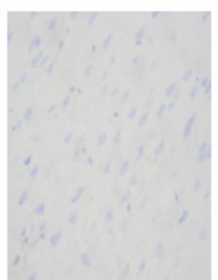

S group

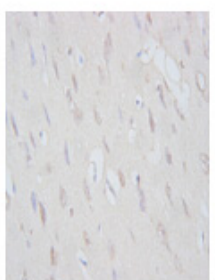

IR group

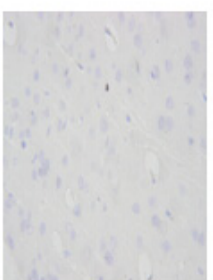

$\mathrm{IR}+\mathrm{T}$ group

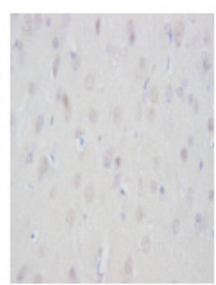

$\mathrm{IR}+\mathrm{T}+\mathrm{L}$ group

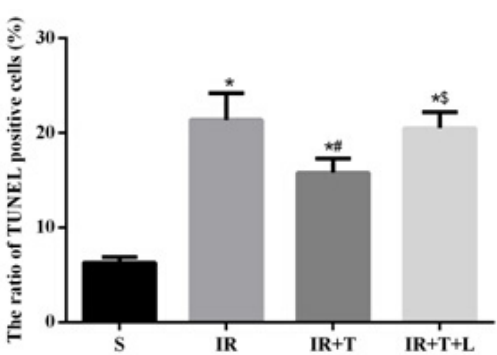

Figure 6 - Expression of apoptosis in the brains (TUNEL). The number of TUNEL positive cells in the brain tissue were increased in IR group when compared with $S$ group $(P<0.05)$. Compared with IR group, TUNEL in IR+T group were significantly lower when TSA was used $(P<0.05)$. While when TSA and LY294002 were joint used, the anti-apoptotic effect of TSA in IR+T group were abolished when compared to the IR+T+L group $(P<0.05)$. ${ }^{*} P<0.05$, vs. S group; ${ }^{\sharp} P<0.05$, vs. IR group; ${ }^{\$} P<0.05$, vs. IR+T group. 
Western blot for cerebral $p$-Akt(Akt) and p-GSK-3B(GSK-36) expression

Compared with $\mathrm{S}$ group, the levels of $p$-Akt and $p-G S K-3 \beta$ in IR group were decreased $(P<0.05)$. TSA treatment in $\mathrm{IR}+\mathrm{T}$ group could significantly increase the expression of $p$-Akt and $p$-GSK-3 $\beta$ when compared with IR group $(P<0.05)$. Whereas, $I \mathrm{R}+\mathrm{T}+\mathrm{L}$ group could significantly decrease the expression of $p$-Akt and $\mathrm{p}-\mathrm{GSK}-3 \beta$ when compared with $\mathrm{IR}+\mathrm{T}$ group $(P<0.05)$ (Figure 7).
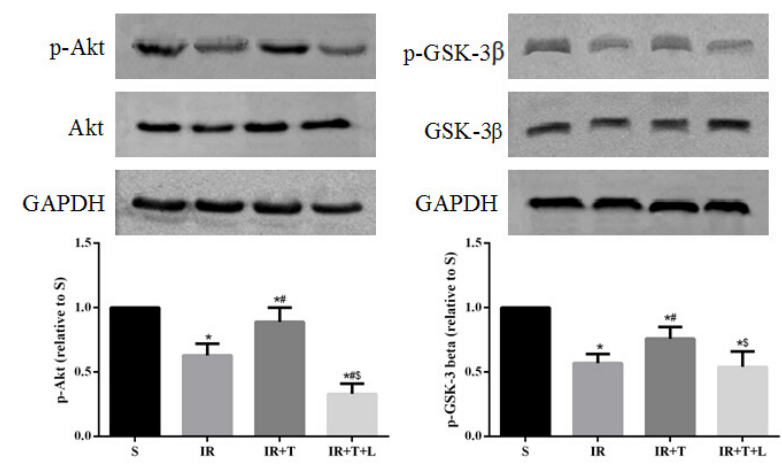

Figure 7 - Western blot for the expression of Akt and GSK-3 $\beta$ in the brains. Cerebral Akt, p-Akt, GSK-3 $\beta, p-G S K-3 \beta$ expression were examined by western blot. As shown, there were no noticeable differences in the expression of total Akt and GSK$3 \beta$ in four groups.The $p$-Akt and $p$-GSK-3 $\beta$ level was markedly decreased in IR group $(P<0.05)$, TSA increased the level of $p$-Akt and $p-G S K-3 \beta$ in IR+T group $(P<0.05)$, However, in $I R+T+L$ group using TSA and LY294002 together, the expression of $p$-Akt and p-GSK-3 $\beta$ protien decreased when compared with $\mathrm{IR}+\mathrm{T}$ group $(P<0.05)$.

${ }^{*} P<0.05$, vs. $S$ group; ${ }^{\sharp} P<0.05$, vs. IR group; ${ }^{\$} P<0.05$, vs. IR+T group.

\section{- Discussion}

The results of this study showed that TSA preconditioning can increase the expression of $p$-Akt, p-GSK-3 $\beta$ and the neuroprotection induced by TSA pretreatment can be blocked by LY294002, which indicating that the Akt/ GSK-3 $\beta$ pathways involved in cerebral ischemia reperfusion injury, and the neuroprotective effect may be partly due to reducing oxidative stress, inflammation and apoptosis. It is proved that the connection between Akt/GSK-3 $\beta$ pathways and TSA in neuroprotective effect against cerebral ischemia reperfusion injury.

There are many hypotheses about the pathogenesis of ischemic stroke, including oxidative stress, inflammatory response, immune regulation, excitatory amino acid toxicity, calcium overload, apoptosis, bloodbrain barrier damage and neurovascular cell interactions ${ }^{13,14}$. There are also many crosseffects among this different hypotheses, which makes the pathogenesis of ischemic stroke more complex ${ }^{15}$. In those hypotheses, oxidative stress and inflammatory response are the most classic, which mainly refers to that a large number of oxidized and inflammatory mediators released after cerebral ischemia reperfusion, leading directly to the functional impairment, affecting the proliferation and apoptosis of neurons, aggravating cerebral ischemia reperfusion injury ${ }^{16,17}$.

Recent studies have shown that the gene expression in ischemic stroke is abnormal, whereas $\mathrm{HDACl}$ can regulate the expression of genes related to neurological function through acetylation/deacetylation by histone and nonhistone, reducing the injury, promoting the revascularization of ischemic area and promoting the neuronal plasticity and functional recovery ${ }^{18,19}$. As a result, $\mathrm{HDACl}$ plays a key role in regulating neurological function and attracts a wide range of concerns as a potential drug target. Studies have shown that $\mathrm{HDACl}$ can inhibit the catalytic activity of HDAC, change the chromosome structure, activate the gene transcription, correct the chromosomes from "closed" to "open" state, play a neuroprotective role, including: inhibition of neuronal apoptosis, regulation of microglia/macrophage polarization, reduction of inflammatory response, promotion of nerve regeneration ${ }^{5,20}$. 
$\mathrm{HDACl}$ not only interacts with histones that regulate gene transcription, but also with non-histones that regulate cell stability. Studies have shown that $\mathrm{HDACl}$ can produce crosstalk in kinase signaling cascades in an animal model of ischemic stroke ${ }^{21,22}$. Our results also confirm that $\mathrm{HDACl}$ has a protective effect in cerebral ischemia reperfusion, which may be associated with activation of Akt/GSK-3 $\beta$ pathway.

GSK-3 $\beta$ is highly expressed in the brain, lungs and kidneys of the human body. Evidences have shown that GSK-3 $\beta$ has a close relationship with oxidative stress, cell apoptosis and inflammatory reaction. It can reduce the release of inflammatory factors and oxygen free radicals by regulating the mitochondrial permeabel transition pore (mPTP) so as to produce a protective effect ${ }^{23,24}$. Meanwhile, GSK-3 $\beta$ is also been proved to have a role in the innumerable downstream effects of Akt, suggesting that Akt/GSK-3 $\beta$ is a very important signaling pathway that has a crucial effect on the progression of many diseases ${ }^{25,26}$. Therefore, the researchers speculated that by regulating the expression of Akt/GSK-3 $\beta$, may have a positive impact on reperfusion injury, which has important clinical value. Our results confirm that after exposure to $\mathrm{HDACl}$, Akt/GSK-3 $\beta$ signaling pathway is activated, which reduces the expression of oxidative stress, apoptosis factor and TUNEL, beneficial to the brain protection. When Akt inhibitor is added, the signal pathway is inhibited and the protective effects induced by TSA is crippled.

It is now generally accepted that neuroinflammation mediated by activated microglia and infiltrating leukocytes, including monocytes/macrophages has a prominent role in ischemia induced brain injury ${ }^{27,28}$. Inflammatory cytokines (TNF- $\alpha$ and IL-1 $\beta$ ), reactive oxygen species(ROS) are overexpressed to induce the inflammatory response. After stroke, many of the leukocytes including monocytes and macrophages move from the blood vessels and accumulate in the infarct zone to contribute to neuroinflammation and neurodegeneration ${ }^{29-31}$. Our results showed that TSA treatment significantly reduced the expression of TNF- $\alpha$, IL-1 $\beta$ and the ROS following MCAO. When Akt inhibitor is added, the signal pathway is inhibited and the protective effects is abolished.

\section{Conclusion}

HDAC inhibitor TSA plays a protective role on cerebral ischemia reperfusion injury by activating the Akt/GSK-3 $\beta$ pathway, inhibiting the activation of this pathway alleviates the protective effects.

\section{References}

1. Park H, Hong $M$, Jhon GJ, Lee $Y$, Suh $M$. Repeated oral administration of human serum albumin protects from the cerebral ischemia in rat brain following MCAO. Exp Neurobiol. 2017;26(3):151-7. PMID: 28680300.

2. Shin DH, Kim GH, Lee JS, Joo IS, Suh-Kim $\mathrm{H}$, Kim SS, Hong JM. Comparison of MSCNeurogenin 1 administration modality in MCAO rat model. Transl Neurosci. 2016;7(1):164-72. PMID: 28270935.

3. van den Berg LA, Dijkgraaf MG, Berkhemer OA, Fransen PS, Beumer D, Lingsma HF, Majoie CB, Dippel DW, van der Lugt A, van Oostenbrugge RJ, van Zwam WH, Roos YB, MR CLEAN Investigators. Two-year outcome after endovascular treatment for acute ischemic stroke. N Engl J Med. 2017;376(14):1341-9. PMID: 28379802.

4. Fessler EB, Chibane FL, Wang Z, Chuang DM. Potential roles of HDAC inhibitors in mitigating ischemia-induced brain damage and facilitating endogenous regeneration and recovery. Curr Pharm Des. 2013;19(28):5105-20. PMID: 23448466.

5. Aune SE, Herr DJ, Kutz CJ, Menick DR. Histone deacetylases exert class-specific roles in conditioning the brain and heart against acute ischemic injury. Front Neurol. 2015;6:145. PMID: 26175715. 
6. Wu Y, Leng $Y$, Meng $Q$, Xue R, Zhao B, Zhan $L$, Xia Z. Suppression of excessive histone deacetylases activity in diabetic hearts attenuates myocardial ischemia/reperfusion injury via mitochondria apoptosis pathway. J Diabetes Res. 2017;2017:8208065. PMID: 28191472.

7. Zhang JF, Zhang L, Shi LL, Zhao ZH, Xu H, Liang F, Li HB, Zhao Y, Xu X, Yang K, Tian YF. Parthenolide attenuates cerebral ischemia/ reperfusion injury via Akt/GSK-3 $\beta$ pathway in PC12 cells. Biomed Pharmacother. 2017;89:1159-65. PMID: 28314243.

8. Wang W, Li M, Wang Y, Wang Z, Zhang W, Guan F, Chen Q, Wang J. GSK-3 $\beta$ as a target for protection against transient cerebral ischemia. Int J Med Sci. 2017;14(4):333-9. PMID: 28553165.

9. Abdel-Aleem GA, Khaleel EF, Mostafa DG, Elberier LK. Neuroprotective effect of resveratrol against brain ischemia reperfusion injury in rats entails reduction of DJ-1 protein expression and activation of PI3K/Akt/GSK3b survival pathway. Arch Physiol Biochem. 2016;122(4):200-13. PMID: 27109835.

10.Reho JJ, Rahmouni K. Oxidative and inflammatory signals in obesity-associated vascular abnormalities. Clin Sci (Lond). 2017;131(14):1689-700. PMID: 28667067.

11.Chisholm NC, Henderson ML, Selvamani A, Park MJ, Dindot S, Miranda RC, Sohrabji F. Histone methylation patterns in astrocytes are influenced by age following ischemia. Epigenetics. 2015;10(2):142-52. PMID: 25565250.

12.Eyupoglu IY, Savaskan NE. Epigenetics in brain tumors: HDACs Take Center Stage. Curr Neuropharmacol. 2016;14(1):48-54. PMID: 26521944.

13.Gao X, Wu B, Fu Z, Zhang Z, Xu G. Carvedilol abrogates hypoxia-induced oxidative stress and neuroinflammation in microglial BV2 cells. Eur J Pharmacol. 2017;S00142999(17):30525-3. PMID: 28821450.

14.Narne P, Pandey V, Phanithi PB. Interplay between mitochondrial metabolism and oxidative stress in ischemic stroke: an epigenetic connection. Mol Cell Neurosci. 2017;82:176-94. PMID: 28552342.

15.Wang CP, Shi YW, Tang M, Zhang XC, Gu Y, Liang XM, Wang ZW, Ding F. Isoquercetin ameliorates cerebral impairment in focal ischemia through anti-oxidative, antiinflammatory, and anti-apoptotic effects in primary culture of rat hippocampal neurons and hippocampal CA1 region of rats. Mol Neurobiol. 2017;54(3):2126-42. PMID: 26924319.

16. Lobo-Silva D, Carriche GM, Castro AG, Roque $S$, Saraiva M. Balancing the immune response in the brain: IL-10 and its regulation. J Neuroinflammation. 2016;13(1):297. PMID: 27881137.

17. Mckee CA, Lukens JR. Emerging roles for the immune system in traumatic brain injury. Front Immunol. 2016;7:556. PMID: 27994591.

18.Yildirim F, Ji S, Kronenberg G, Barco A, Olivares R, Benito E, Dirnagl U, Gertz K, Endres $M$, Harms $C$, Meisel A. Histone acetylation and CREB binding protein are required for neuronal resistance against ischemic injury. PLoS One. 2014;9(4):e95465. PMID: 24748101.

19.Ganai SA, Ramadoss M, Mahadevan V. Histone Deacetylase (HDAC) Inhibitorsemerging roles in neuronal memory, learning, synaptic plasticity and neural regeneration. Curr Neuropharmacol. 2016;14(1):55-71. PMID: 26487502.

20.Tchio Mantho $\mathrm{Cl}$, Harbuzariu A, GonzalezPerez RR. Histone deacetylases, microRNA and leptin crosstalk in pancreatic cancer. World J Clin Oncol. 2017;8(3):178-89. PMID: 28638788.

21.Roos WP, Krumm A. The multifaceted influence of histone deacetylases on DNA damage signalling and DNA repair. Nucleic Acids Res. 2016;44(21):10017-30. PMID: 27738139.

22. Wen X, Huang A, Hu J, Zhong Z, Liu Y, Li $Z$, Pan $X$, Liu Z. Neuroprotective effect of astaxanthin against glutamate-induced cytotoxicity in HT22 cells: involvement of the Akt/GSK-3ß pathway. Neuroscience. 2015;303:558-68. PMID: 26197224.

23. Luo L, Chen J, Su D, Chen M, Luo B, Pi R, Wang L, Shen W, Wang R. L-F001, a multifunction ROCK inhibitor prevents 6-OHDA induced cell death through activating Akt/GSK-3beta and Nrf2/HO-1 signaling pathway in PC12 cells and attenuates MPTP-induced dopamine neuron toxicity in mice. Neurochem Res. 2017;42(2):615-24. PMID: 28078613.

24.Cai L, Li Y, Zhang Q, Sun H, Yan X, Hua T, 
Zhu Q, Xu H, Fu H. Salidroside protects rat liver against ischemia/reperfusion injury by regulating the GSK-3 $\beta / N r f 2-d e p e n d e n t$ antioxidant response and mitochondrial permeability transition. Eur J Pharmacol. 2017;806:32-42. PMID: 28411054.

25.Qi Y, Dou DQ, Jiang $H$, Zhang BB, Qin WY, Kang K, Zhang N, Jia D. Arctigenin attenuates learning and memory deficits through PI3k/Akt/GSK-3 $\beta$ pathway reducing tau hyperphosphorylation in $A \beta$-Induced $A D$ Mice. Planta Med. 2017;83(1-02):51-6. PMID: 27224270.

26. Huang JY, Ma YZ, Yuan YH, Zuo W, Chu SF, Liu $\mathrm{H}$, Du GH, Zhang DM, Chen NH. Claulansine $F$ promoted the neuronal differentiation of neural stem and progenitor cells through Akt/GSK-3 $\beta / \beta$-catenin pathway. Eur J Pharmacol. 2016;786:72-84. PMID: 27179990.

27.Kim H, Bae S, Kwon KY, Hwang YI, Kang JS, Lee WJ. A combinational effect of acetaminophen and oriental herbs on the regulation of inflammatory mediators in microglia cell line, BV2. Anat Cell Biol. 2015;48(4):244-50. PMID: 26770874.

28.Lee JW, Nam H, Yu SW. Systematic analysis of translocator protein $18 \mathrm{kDa}$ (TSPO) ligands on toll-like receptors-mediated proinflammatory responses in microglia and astrocytes. Exp Neurobiol. 2016;25(5):2628. PMID: 27790060.

29.Sharma S, Taliyan R. Synergistic effects of GSK-3 $\beta$ and HDAC inhibitors in intracerebroventricular streptozotocininduced cognitive deficits in rats. Naunyn Schmiedebergs Arch Pharmacol. 2015;388(3):337-49. PMID: 25547373.

30.Fan Y, Xie L, Chung CY. Signaling pathways controlling microglia chemotaxis. Mol Cells. 2017;40(3):163-8. PMID: 28301917.

31. He Q, Li Z, Wang Y, Hou Y, Li L, Zhao J. Resveratrol alleviates cerebral ischemia/ reperfusion injury in rats by inhibiting NLRP3 inflammasome activation through Sirt1-dependent autophagy induction. Int Immunopharmacol. 2017;50:208-15. PMID: 28683365.

\section{Correspondence:}

Wenwei Gao

Department of Critical Care Medicine, Renmin

Hospital, Wuhan University

99 Zhang Rd, Wuhan 430060

Hubei China

wenwei_gao@163.com

Received: June 12, 2017

Review: Aug 14, 2017

Accepted: Sept 18, 2017

\section{Conflict of interest: none}

Financial sources: National Natural Science

Foundation of China (Grant no 81471844), and Natural Science Foundation of Hubei Province (2016CFB167, 2017CFB267).
${ }^{1}$ Research performed at Department of Anesthesiology, Renmin Hospital, Wuhan University, China. 